\title{
O FUNDO ESTÉTICO DA GESTALT-TERAPIA ${ }^{1}$
}

MÔNICA BOTELHO ALVIM

\begin{abstract}
Resumo: Neste artigo mapeamos as relações da Gestalt-Terapia com a Arte e a Estética a partir da história do envolvimento pessoal de três dos principais formuladores da Gestalt-Terapia: Fritz Perls, Laura Perls e Paul Goodman. Consideramos que suas experiências pessoais com a arte constituem um fundo estético de onde partem as experiências da Gestalt-Terapia. Descrevemos o envolvimento de Fritz com o teatro, de Laura com a dança e de Goodman com a literatura, pesquisando elementos históricos e conceituais que nos permitam mapear e traçar alguns contornos de um corpo teórico que tem como importantes referenciais, para a apreciação da forma ou gestalt, os critérios estéticos. Tais critérios estão na base da proposta da Gestalt-Terapia de um método psicoterápico fundamentado na experimentação que toma como tarefa principal trabalhar com a estrutura da experiência aquiagora. Tal método busca refazer as relações dinâmicas da figura-fundo até que se forme uma Gestalt vigorosa, expressando que o contato se intensificou, que há awareness e que o movimento ou comportamento presente está energizado. Consideramos que a vivência com a arte constituiu um fundo que dirigiu o olhar dos fundadores da Gestalt-Terapia para o viés fenomenológico.
\end{abstract}

Palavras-chave: Arte, Estética, Gestalt-Terapia, Experimentação.

\section{Introdução}

"Os conceitos básicos da gestalt são filosóficos e estéticos”

Laura Perls

Fundada em 1951, a partir da publicação do livro Gestalt-Terapia, de F. Perls, R. Hefferline e P. Goodman, a Gestalt-Terapia traz uma proposta de psicoterapia que se baseia em uma visão do homem e da sociedade, constituindose em uma teoria acerca de suas relações. Tomou como ponto de partida a psicanálise freudiana, primeira formação de Fritz e Laura Perls, e foi formulada a partir de teorias psicológicas quem vêm sendo discutidas e aprofundadas, ao longo dos anos, no âmbito da abordagem, com o objetivo de melhor fundamentar suas origens históricas e cabedal teórico. Ribeiro (1985) foi o primeiro autor brasileiro a sistematizar as teorias e filosofias de base da Gestalt-Terapia: Psicologia da Gestalt, Teoria de Campo, Teoria Organísmica, Teoria Holística, Humanismo, Existencialismo e Fenomenologia, em um trabalho que mapeia e discute os elementos teóricos que sustentam a teoria da Gestalt-Terapia.

\footnotetext{
${ }^{1}$ Parte integrante da Tese de Doutorado em Psicologia Clínica, defendida na Universidade de Brasília, intitulada "Ato Artístico e Ato Psicoterápico como Experiment-ação: diálogos entre a fenomenologia de Merleau-Ponty, a arte de Lygia Clark e a Gestalt-Terapia”, sob orientação do Dr.Jorge Ponciano Ribeiro, em março de 2007.
} 
A publicação do livro Gestalt-Terapia é a concretização de uma nova psicoterapia que vinha sendo gestada desde o surgimento das divergências de Fritz e Laura Perls com aspectos da psicanálise que praticavam naquele período. Tais divergências puderam ser explicitadas e discutidas no livro Ego, Fome e Agressão: uma revisão da teoria e do método de Freud, publicado originalmente em 1942, na África do Sul. Fritz Perls, com a contribuição fundamental de Laura Perls - profunda conhecedora da psicologia da gestalt e da teoria organísmica de Kurt Goldstein - esboça naquela obra algumas idéias que se constituem nas bases da então futura Gestalt-Terapia.

Neste trabalho tomamos como tarefa principal reunir alguns elementos históricos que permitam enriquecer o fundo da Gestalt-Terapia. Partimos de uma tese (Alvim, 2007) que discute a experiment-ação em Gestalt-Terapia, e, com esse norte, enfatizamos os elementos históricos e conceituais que nos permitem mapear e traçar alguns contornos de um corpo teórico que dê sustentação para sua proposta de um método psicoterápico fundamentado na experimentação.

Além das origens formalmente descritas, influências diretas e indiretas de outras abordagens e pensamentos foram a ela trazidos por meio das trajetórias existenciais - pessoais e profissionais - de seus fundadores. Acreditamos que suas convergências e divergências teóricas se deram a partir de uma relação dialética de identidade e diferença, orientada por suas visões de mundo, crenças e experiências pessoais anteriores, um fundo de existência pessoal de Fritz Perls, Laura Perls, Paul Goodman e demais colaboradores que tem em comum o contato deles com a arte. É nesse sentido que mapeamos alguns elementos que constituem esse vivido, compondo um "fundo estético" de onde partem as experiências da Gestalt-Terapia.

\section{O Fundo Estético da Gestalt-Terapia: vivências com a arte}

"Ser um artista é funcionar de modo holístico. E ser um bom terapeuta também significa isso". Laura Perls

"Os conceitos básicos da Gestalt são filosóficos e estéticos", afirma Laura Perls (1992, p.149). Ela e Paul Goodman são responsáveis por trazer uma preocupação com a natureza da arte para formular a Gestalt-Terapia, uma abordagem plantada firmemente em um contexto de valores estéticos tanto quanto de idéias psicológicas (Miller, 1980).

A Gestalt-Terapia foi concebida por pensadores e clínicos que eram envolvidos em disciplinas artísticas, tais como literatura, música, dança e teatro (Alvim, 2006). Eles "encontraram nas artes uma visão de funcionamento ideal, a qual eles estenderam a toda atividade humana. Essa visão tornou-se a sua medida de saúde e doença e guiou sua prática em psicoterapia” (Miller, 1980, p.86). Laura Perls afirmou que a terapia é mais arte que ciência, no sentido de que necessita de 
muita intuição e sensibilidade e que vai muito além de uma abordagem associativa. Para ela, "ser um artista é funcionar de modo holístico" (Perls, 1992, p.20).

Fritz Perls, Laura Perls e Paul Goodman foram os três principais formuladores da Gestalt-Terapia. Todos eles estiveram profundamente envolvidos com a arte ao longo de suas vidas. Fritz Perls desde a infância esteve envolvido com o teatro, que praticou formalmente na adolescência, quando participou da escola de teatro de Max Reinhardt; Laura, desde a infância como pianista e depois com a dança e a literatura; Goodman como poeta e escritor.

Isso nos instiga a recorrer às suas histórias pessoais na busca de experiências que compuseram o fundo que está refletido, de modo implícito, na forma da GestaltTerapia, refletido em sua ação essencialmente experiencial.

Fritz Perls e Laura eram alemães. Ambos viveram naquele país durante os primeiros anos do século XX e respiraram os ares da modernidade artística européia, o movimento construtivista alemão, a Bauhaus, e a grande efervescência cultural interrompida bruscamente com a ascensão de Hitler ao poder.

Fritz Perls, na adolescência, estudou teatro na escola de Max Reinhardt. Desde a infância, porém, já se sentiu atraído pelo teatro. Em seu livro de memórias ele ressalta o fascínio que o mundo do circo e do teatro exerceram sobre ele e pergunta: “estaria tal mundo fora do meu alcance?", para em seguida responder: “talvez não (...) algum dia, quem sabe, algum dia...” (Perls, 1969/1979, p.321). O contato com o teatro se deu em casa, um vizinho dava seus primeiros passos como ator e diretor e Fritz fazia pequenas tarefas, assistia aos ensaios, mais tarde viajando com sua trupe para pequenas cidades.

Depois de uma grande crise escolar no início da adolescência - que trouxe sua expulsão da escola e uma decisão do pai de colocá-lo para trabalhar - foi matriculado em uma escola de educação mais liberal onde se sentiu novamente livre, integrado e onde se envolveu com as aulas de teatro. Participava neste período do Teatro Real, fazendo "bicos" como estudante. Acerca disso afirmou: "adorávamos as roupas e a participação, e a tomada de contato com a literatura de uma forma vívida" (Perls, 1969/1979, p.322). Depois vai para o Deutsche Theather, onde também atua como assistente. Lá conhece Max Reinhardt, que trabalhava como encarregado. Afirma: "Reinhardt foi o primeiro gênio criativo que conheci" (Perls, 1969/1979, p.322). Importante influenciador do expressionismo alemão no teatro, o dramaturgo desenvolveu um novo estilo de trabalho que preconizava a expressividade e a subjetividade. De acordo com Fonseca (s.d.)

Fundamentalmente, o teatro naturalista de Max Reinhardt, que será uma influência fundamental no desenvolvimento do teatro e do cinema expressionistas, buscava a coragem na expressividade e interpretação da singularidade pessoal. Reinhardt abandonou a perspectiva de todo Realismo, em direção ao Expressionismo. Ou seja, em direção a uma interpretação que se centrava no privilégio da vivência subjetiva, e na sua expressividade performática, sem uma submissão à reprodução de uma realidade objetiva. 
Em busca da expressividade, Reinhardt, do mesmo modo que artistas modernos e contemporâneos fariam um pouco mais tarde, ultrapassou as fronteiras entre artista e público. Tinha como alvo provocar a expressividade do espectador, que também atuava como participante no contexto da obra. "Nada permanecia intocado, até que a peça transcendesse para um mundo de realidade, mas ainda com bastante espaço para a fantasia da audiência”, descreve Perls (1969/1979, p.322). Fonseca (s.d.) ressalta o caráter existencial da proposta do dramaturgo:

Na medida em que buscava reduzir, e mesmo eliminar, a distância entre atores e espectadores, a distância entre o palco/atores e a platéia/público, Reinhardt militava experimental e poderosamente pela idéia de que a arte cênica não é uma arte apenas de artistas formais, não é meramente uma arte do palco. Na verdade somos, todos, efetivamente atores e artistas, e carecemos fundamentalmente de exercermo-nos efetivamente como tais. Uma vez que esta condição constitui-se como a qualidade básica da existência e da condição humana.

Talvez o fascínio de Perls pelo teatro estivesse envolvido com esse apelo, implícito no trabalho de Reinhardt. A crise na adolescência refletia a inquietude de Perls com o tradicionalismo autoritário dos pais, rígidos, que dele tentaram subtrair a possibilidade expressiva espontânea. A superação da crise envolveu o teatro e a expressividade. "Eu penetrara na vida da existência múltipla", afirma, referindo-se às diferentes atividades e possibilidades presentes em sua vida a partir do teatro.

O estilo de Reinhardt, que preconizava a harmonia e o ritmo na interpretação, enfatizava a comunicação não-verbal, tendo influenciado Fritz e a Gestalt-Terapia, que toma a harmonia e ritmo da forma como indicadores de que a ação em curso é saudável, é uma ação que envolve o organismo como um todo. Nesse sentido, a Gestalt-Terapia enfatiza a consonância indispensável entre palavras, gesticulação corporal e ação, como fazia Fritz Perls: "Ele estava alerta à sutileza, à musicalidade nas vozes e indicava prontamente quando o tom ou ritmo da voz não soavam verdadeiros" (Shepard, 1975, p.22). Não buscava, nesse sentido, uma representação do papel, mas sua apresentação, que incluía uma tensão entre o público e o artista. A naturalidade era o requisito central em seu trabalho, que sacrificava qualquer recurso ou artifício em favor de "uma realidade interacional que é expandida, construindo uma tensão entre os personagens e entre os atores e $o$ público" (Shepard, 1975, p.25). Essa tensão está refletida em nossa noção de campo organismo-ambiente, que descreve o contato como um encontro que envolve diferença e agressividade, manipulação e assimilação. Uma tensão dialética que pode ser compreendida do ponto de vista organísmico - tal como proposto por Merleau-Ponty - como produtora de relações novas, portadoras e expressivas de significação. A significação se mostra na forma e as categorias estéticas são as melhores referências para o acesso a ela. Ao descrever aquilo a que se referiu como genial em Reinhardt, Perls ressalta o valor estético do ritmo: 
Com infinita paciência, ele ensaiava os participantes até que suas vozes se ajustassem e combinassem. Ele compreendia o ritmo das tensões e do silêncio, de modo que a prosa se transformava em música. A tragédia de Édipo, apresentada numa grande arena com centenas de pessoas berrando por socorro num ritmo sustentado por um gongo, revelando, implacavelmente, a culpa sem culpa do homem (Perls, 1969/1979, p.323).

O ritmo da estrutura orgânica só pode ser visto, sentido e descrito. A atenção de Reinhardt ao ritmo e à musicalidade da estrutura parece ser uma experiência vivida por Perls que se reflete significativamente no modo gestáltico de atenção à forma, à estrutura, à totalidade da estrutura. A "perseguição implacável" da naturalidade do gesto e da voz que fazia o dramaturgo parece presente no modo arguto como Perls identificava aquilo que chamava de dramatizações - muitas vezes sutis - de seus pacientes. Perls lidava com essas situações com impaciência, ironia, visando frustrar o "drama”, estilo que gerou para ele muitas críticas e para a Gestalt-Terapia alguns malentendidos. A interação com o público em uma mesma estrutura é uma nuance refletida no tipo de relação terapêutica proposta depois pela Gestalt-Terapia, focada na estrutura da relação, na experiência no campo, experiência bruta que envolve uma tensão entre eu e outro. A busca dessa psicoterapia de refazer as relações dinâmicas no campo organismo-ambiente até que se forme uma gestalt vigorosa, vívida e com brilho, parece refletir o estilo de trabalho de Reinhardt, assim como um desejo da Gestalt-Terapia de re-encontrar a musicalidade da existência humana.

\section{Ritmo e Musicalidade}

A musicalidade e o ritmo estão na formação de Fritz Perls como estão também na formação de Laura Perls. Ela considera que a música foi o treinamento mais importante que teve desde muito cedo em sua vida. Sua mãe tocava piano muito bem e Laura começou a tocá-lo aos cinco anos. "Eu era capaz de ler partituras musicais muito antes de ler qualquer outra coisa", afirmou (Perls, 1992, p.3). A dança entrou em sua vida aos oito anos e o trabalho corporal ligado à musica e à dança foi uma tônica na vida pessoal e no trabalho de Laura Perls. Estudou e praticou, ao longo de toda a vida, dança moderna e Euritmia (Perls, 1992), um tipo de trabalho desenvolvido por Émile Jacques-Dalcroze (1865-1950), um suíço. Seu sistema, que ficou conhecido como Dalcroze Eurhythmics de Treinamento Musical, buscava transformar o sentido rítmico em experiência corporal, o que significava experimentar a música pelo movimento corporal. Essa foi uma grande influência para a Gestalt-Terapia.

Laura também estudou desde cedo o trabalho de Ludwig Klages, denominado movimento expressivo e criatividade e experimentou os métodos de Alexander e Feldenkrais "muito antes do desenvolvimento da Bioenergética e de outras terapias corporais", afirmou (Perls, 1992, p.151). 
Isso resultou, entre outras coisas, em um estilo de terapia que acentuava o corpo. Considerava o trabalho com o corpo fundamental: "estou trabalhando muito com isso em meus grupos de treinamento porque acho que é um dos suportes essenciais", relata (Perls, 1992, p.3). Considerava que este trabalho estava conectado com o conceito de organismo como totalidade, de Kurt Goldstein (Perls, 1992). Considera que todos os distúrbios adquiridos durante o desenvolvimento interferem com a liberdade do organismo para se orientar e manipular no ambiente e envolvem o sistema muscular voluntário. Afirma que a teoria reichiana desenvolve bem esse raciocínio, mas que ela própria já havia se dado conta disso há muito tempo a partir de sua experiência com a dança (Perls, 1992). Partindo dessa experiência, busca desenvolver um trabalho de fortalecimento da base corporal e de ampliação da respiração, para que o corpo esteja livre para a orientação e manipulação.

Tal posição, adquirida por Laura a partir de sua experiência com a música e a dança, foi definidora na concepção da Gestalt-Terapia, que acentua a corporeidade - por esta influência de Laura e também pela influência reichiana que tiveram Perls $^{2}$ e Goodman. Acentuar a corporeidade não significa necessariamente desenvolver com o cliente um trabalho corporal, como Laura fazia - aliás, essa não é característica definidora da Gestalt-Terapia. Significa, sim, trabalhar com a awareness, buscando assentar o trabalho psicoterápico na forma (corporal) que se apresenta. Isso significa utilizar como diretoras do olhar do terapeuta - e do cliente sobre si mesmo - categorias estéticas como ritmo, fluidez, vitalidade, brilho, harmonia, musicalidade. $\mathrm{O}$ andar de alguém, o modo como se posta de pé, sentado, os movimentos que realiza enquanto fala sobre algo, ou quando fica em silêncio, são formas que se configuram a partir de sua relação com o terapeuta e é com esse material em estado bruto que começamos o trabalho de ampliação de awareness. De que modo as formas me aparecem? Têm harmonia? Ritmo? Brilho? Musicalidade? Como estou (terapeuta) implicado na formação das formas? Todas essas são questões orientadoras do trabalho do psicoterapeuta gestáltico.

A formação moderna dos Perls, fomentada no seio da cultura moderna alemã, o contato com a arte desde muito cedo, contribuiu essencialmente para que ambos pudessem desenvolver uma visão de mundo mais alinhada com o pensamento complexo e com uma linguagem da sensibilidade, distanciada do racionalismo. Tal linguagem, como propõe Malevitch (citado por Gullar, 1999, p.136) "nos permite apreender uma dimensão recôndita de nossa experiência". Seu contato com teorias e pensadores que derivavam para um viés organísmico e holístico se soma ao contato com a arte na formulação de um estilo de psicoterapia que preconiza o movimento dialético de busca da significação das formas, que se configuram e reconfiguram, exigindo - para acessá-las - uma atenção ao movimento e à ação. Eis a experiência. A experimentação que os movimenta na passagem da interpretação analítica que faziam

${ }^{2}$ De acordo com Laura (1992, p.8), Fritz esteve em análise com Wilhelm Reich por dois anos "absolutamente fascinado" e teria continuado com ele (trabalhando) se Hitler não houvesse ascendido ao poder, já que em função disso Reich abandonou a Alemanha antes de Perls. 
no início de sua prática para a síntese da experiência imediata expressa na ação (corpórea) presente. Talvez a vivência e formação de Fritz e Laura, aqui brevemente descritas, tenham contribuído para o distanciamento de ambos da psicanálise, que estava construída sobre as bases de um pensamento analítico desenvolvido por Sigmund Freud, que encontrava algumas arestas com os paradigmas da arte moderna.

\section{A Contribuição de Paul Goodman}

O contato com as artes como parte fundamental da educação e os "ares bauhausianos" respirados por Fritz e Laura refletem-se também numa certa vocação social da Gestalt-Terapia. Perls fazia parte da comunidade boêmia de Berlim e convivia com os artistas, poetas e intelectuais de esquerda da época, incluindo membros da Bauhaus (Clarkson \& Mackewn, 1993). O movimento artístico em torno daquela escola preconizou a arte e a expressão estética como fator natural da vida. A proposta da Bauhaus de promover uma educação estética das massas se assentava na idéia de que a sociedade estava enferma e que a arte e a expressão estética deveria ser resgatada para reintegrar o homem ao mundo social. A idéia de uma sociedade enferma, racionalista, dicotômica e distanciada da espontaneidade expressiva também é marca da Gestalt-Terapia, que tem um ideal social e comunitário, desenvolvido tanto por influência dos ares bauhausianos quanto por influência de Paul Goodman.

Paul Goodman era um escritor, PhD em Literatura pela Universidade de Chicago, a qual, de acordo com Bloom (2003, p.71) era naquele período um centro de referência do pragmatismo americano. O autor ressalta essa influência na GestaltTerapia trazida por Goodman: "Goodman credita James e Dewey como influências significativas em seu trabalho (...) suas descrições líricas da experiência”. Sua obra foi ampla, incluindo política e economia, urbanismo, educação e psicoterapia, tendo produzido livros e inúmeros ensaios de crítica social. No entanto, a dimensão da escrita artística era primordial para ele, que se considerava "fundamentalmente novelista e poeta" (Roszak, 1969/1972, p.185). Sua carreira parte daí. Poeta, novelista e ensaísta, Goodman produziu uma obra ficcional que, de acordo com Roszak (1969/1972), gerou sua filosofia social e cunhou seu estilo.

Goodman sempre assumiu uma postura pessoal e social peculiar, independente, e desafiadora das leis e normas sociais impostas. Sua produção refletia esse estilo, o que gerava um incômodo e resistência no público.

Sua obra é permeada por uma espécie de astúcia agressiva, que nunca deixa de ferir algum ponto vulnerável de nosso bom senso convencional. Seu tom característico de argumentação consiste numa negação radical e irônica de tudo quanto se supõe ser verdadeiro, acompanhado de uma disposição ainda mais irritante de iniciar a reeducação do leitor ali mesmo, a partir do zero (Roszak, 1969/1972, p.185).

Podemos aqui vislumbrar uma arte com nuances modernas. Desafiadora e irônica, nega a verdade estabelecida e atinge o espectador em suas representações, tornando-se incômoda, inquietante, aproximando-se da noção de força satânica 
definida por Karl (1988) ao discutir o movimento de vanguarda da arte moderna, como aquela que promove um afastamento do prescrito, do curso normal, produzindo um contraditório.

Assumiu desde muito cedo uma atitude política independente, anarquista, mais como um estilo de vida que como uma ideologia definida. Suas atividades políticas eram centradas em torno do Spanish Anarchist Hall - Solidaridade Internacional Anti-Fascista - , em Nova York (Anarchist Archives, 2007). O anarquismo de Goodman era mais atitudinal que ideológico, uma espécie de inquietude. Ele não acreditava numa autoridade centralizada, era sempre pragmático em sua abordagem da mudança. Sua preocupação era com o aqui, agora e, como enfatiza Stoehr (1994/1999), no que a pessoa pode fazer então. Seu foco era na experiência cotidiana: o que perturba as pessoas, pelo que elas anseiam, o que restringe sua habilidade para criar. Goodman rejeitava jargões acadêmicos e esquemas teóricos (Jezer, s/d), refletindo as influências do pragmatismo.

Até os anos 50, quando teve contato com Perls, Goodman era essencialmente um artista e seu trabalho era a escrita literária: poemas, textos para teatro e estórias curtas. Trabalhava como autônomo em revistas literárias e grupos de teatro, mas seu estilo vanguardista não propiciava grande aceitação (Anarchist Archives, 2007). Nesse período sua roda de colegas e interlocutores incluía Merce Cunningham, John Cage, Andy Wahrol, Jaspers Johns, o Living Theatre - que encenou textos seus - todos eles artistas que desenvolviam experiências em seus trabalhos imbuídos de um "espírito moderno".

A companhia de dança Merce Cunningham, por exemplo, fundada em 1953, era dirigida por Merce e John Cage, que trabalhavam as coreografias e a música com base em seqüências improvisadas e considerando intencionalmente o acaso. Eles compunham movimentos básicos e definiam a estrutura da coreografia, ou seja, direção, seqüência, número de repetições, tipo de movimento, etc. a partir da utilização de um método do acaso: dados e oráculos eram consultados para definir direções e movimentos de suas coreografias. Cage, o diretor musical, emprestava um estilo de certo modo exótico às composições que causavam estranheza no público. Alterava a divisão silábica das palavras, compunha textos que se adequassem ao ritmo da coreografia, e não o contrário. A pretensão deles era de criar a partir do movimento, da ação, fazendo uma dança "não-representativa".

O Living Theatre foi fundado em 1947, em Nova York, por Judith Malina e Julian Beck, como uma alternativa ao teatro convencional comercial. O nome Living Theatre ou "teatro vivente" faz alusão à sua proposta vanguardista de envolvimento com a vida, com o público e o improviso. Nos anos 1960 e 1970 o grupo passou a viajar o mundo inteiro e "evoluiu para um coletivo, que vivia e trabalhava junto na direção da criação de uma nova forma de atuação não-ficcional baseada no comprometimento político e físico dos atores com a utilização do teatro como meio de fomentar mudança social”.

${ }^{3}$ (http://www.livingtheatre.org/abou/history.html. Consultado em 10.01.2007) 
Os amplos conhecimentos e vivências de Goodman em vários campos como política, arte, sociologia, economia, aliados à sua participação intensa nos grupos de vanguarda, também contribuem para a constituição desse fundo que sustenta a GestaltTerapia e que reflete, em sua forma, um espírito moderno, identificado com a ação de vanguarda, quando enfatiza a experiência no mundo, a contingência, a diferença e o improviso criativo na criação de novos significados para existência.

Esse foco na experiência é busca central da fenomenologia. A ênfase na experiência pré-reflexiva, no vivido, no trabalho perceptivo a partir do encontro no mundo com o diferente e estranho - a paisagem áspera a qual se referiu MerleauPonty - são vistas como a possibilidade de retomar a unidade do homem, cindido entre razão e sensibilidade, mente e corpo.

A arte moderna caminha nessa direção e toma um caminho que leva à desnaturalização da percepção, o que se expressa na pintura através do abandono gradual da perspectiva, liberando o olhar antes fixado por ela. Desse modo, introduz uma espécie de desorganização, desequilíbrio e aspereza no quadro, exigindo do espectador um trabalho perceptivo - o que significa falar de um engajamento corporal, sensível. É nesse sentido que Cézanne dá os primeiros passos na direção de uma pintura que dá a ver livremente a coexistência das coisas percebidas, onde o espectador reencontra o mundo tal como em sua experiência vivida, sendo convidado, pela pintura, a restabelecer contato com um logos sensível que brota de sua experiência.

A estética traz em sua origem a discussão do dualismo. Sua fundação como disciplina autônoma, significa que o domínio da sensibilidade obtém direito de cidadania; a intuição e a sensibilidade não são mais as "mestras do erro e $d a$ falsidade" (Jimenez, 1997/2000, p.25). Cabe, então, também à estética, a tarefa de conciliar o dualismo fundamental do homem constituído de natureza e de cultura. "Uma história da estética (...) conta a história da sensibilidade, do imaginário e dos discursos que procuraram valorizar o conhecimento sensível dito inferior, como contraponto ao privilégio concedido, na civilização ocidental, ao conhecimento racional" (Jimenez, 1997/2000, p.25). A noção de experiência estética envolve um ato corporal, um encontro do espectador com qualidades afetivas do objeto, uma relação intencional. De acordo com Dufrenne (2004, p.13), “a experiência estética se situa na origem, naquele ponto em que o homem, confundido inteiramente com as coisas, experimenta sua familiaridade com o mundo".

A vivência de Goodman, Perls e Laura com a arte lhes ofereceram a oportunidade de uma "educação estética”. As experiências de Laura com a literatura, a música, a dança e a expressividade corporal; as de Perls com o teatro expressivo buscando a espontaneidade, harmonia e ritmo na ação; a formação moderna de Goodman e sua vivência como poeta os constituíram. Habitam seu fundo como vividos que convidam seu olhar para a sensibilidade e atenção à forma da experiência - o que se refletiu na Gestalt-Terapia que fizeram. As categorias estéticas, critérios da forma expressiva, estão no fundo da Gestalt-Terapia, influenciando seu olhar sobre o fenômeno humano no mundo. 
Em torno da atenção à forma se imbricam Arte, Estética, Gestalt-Terapia e Fenomenologia. A Psicologia da Gestalt, a Teoria Organísmica e o Holismo compreendem o comportamento como forma, estrutura organismo-ambiente. Consideramos que ao tomar contato com o viés fenomenológico a partir dessas propostas, Perls e Laura enxergaram uma identidade e vislumbraram uma filosofia que refletia aquilo que talvez nem eles soubessem, uma dimensão vivida invisível, mas que estava ali desde muito tempo. A afirmação de Laura Perls de que os conceitos da Gestalt-Terapia são filosóficos e estéticos nos soam como a expressão desse vivido que orienta um caminho em direção à fenomenologia - e que oferece mais alguns elementos para a constituição de uma Gestalt-Terapia centrada na experiment-ação. As propostas teóricas encontradas na fenomenologia fizeram coro com o fundo estético e permitiram que a Gestalt-Terapia transformasse o espaço da psicoterapia em espacializ-ação, enfatizando a experiência vivida e temporalizada como o elemento condutor da significação do mundo.

\section{Referências Bibliográficas}

Alvim, M. B. (2006). Experience esthétique et corporeité. In Jean-Marie Robine (Org.). La psychothérapie comme esthétique [p.43-54]. Bordeaux: LÉxprimerie.

Alvim, M. B. (2007). Ato artístico e ato psicoterápico como Experiment-ação: diálogos entre a fenomenologia de Merleau-Ponty, a arte de Lygia Clark e a GestaltTerapia. Tese de Doutorado em Psicologia. Universidade de Brasília, Brasília.

Anarchist Archives (2007). Paul Goodman: annotated bibliography. (Acessado em 11 de janeiro de 2007). Disponível na World Wide Web em:

http://dwardmac.pitzer.edu/ANARCHIST_ARCHIVES/bright/goodman/ goodman-bio.html

Bloom (2003). "Tiger! Tiger! Burning bright” - Aesthetics values as clinical values in Gestalt Therapy. In M.S.Lobb. \& N. Amendt-Lion (Eds.). Creative License: The art of Gestalt Therapy. Austria: Springer-Verlag Wien New York.

Clarkson, P. \& Mackewn, J. (1993). Fritz Perls. London: Sage Publications.

Dufrenne, M. (1981/2004). Estética e Filosofia. São Paulo: Editora Perspectiva.

Fonseca, A. H. L. (s.d.). Interpretando Max Reinhardt: o que intentava Max Rheinhardt? O que com ele aprendeu Perls e a Gestalt-Terapia? (Acessado em 05 de agosto de 2006), Laboratório Experimental de Psicologia e Psicoterapia Fenomenológico Existencial. Disponível na World Wide Web em: http://www.geocities.com/eksistencia/. 
Gullar, F. (1999). Etapas da arte contemporânea: do cubismo à arte neoconcreta. Rio de Janeiro: Ed. Revan.

Jezer, M. (s.d). Crazy hope \& finite experience: final essays of Paul Goodman. Book review (Acessado em 11 de janeiro de 2007). Disponível na World Wide Web em: http://www.zmag.org/zmag/articles/may95jezer.htm.

Jimenez, M. (1997/2000). O que é estética? Rio Grande do Sul: Editora Unisinos.

Karl, F. R. (1988). O moderno e o modernismo: a soberania do artista 1885-1925. Rio de Janeiro: Imago Editora.

Miller, M. V. (1980). Notes on Art and Symptoms. The Gestalt Journal, Vol. 3, No. 1, Spring, 86-98.

Miller, M. V. (1994). The Poetics of Theory. In T. Stoehr (Org.) Nature Heals: The Psychological Essays of Paul Goodman (Natura sanat non medicus). The Gestalt Journal Press, New York. (Acessado em 11 de Janeiro de 2007). Disponível na World Wide Web em: http://www.gestalt.org/goodman.htm

Perls, F. (1942/2002). Ego, Fome e Agressão: uma revisão da teoria e do método de Freud. São Paulo: Summus.

Perls, F. (1969/1979). Escarafunchando Fritz: dentro e fora da lata do lixo. São Paulo: Summus.

Perls, F. Hefferline, R. \& Goodman, P. (1951/1997). Gestalt-Terapia. São Paulo: Summus.

Perls, L. (1992). Living at the boundary. New York: The Gestalt Journal Press.

Ribeiro, J. P. (1985). Gestalt-Terapia: Refazendo um Caminho. São Paulo: Summus Editorial.

Roszak, T. (1969/1972). A contracultura: reflexões sobre a sociedade tecnocrática e a oposição juvenil. Petrópolis: Vozes.

Shepard (1975). Fritz, an intimate Portrait of Fritz Perls and Gestalt Therapy. New York: Saturday Review Press, E.P.Dutton \& Co, Inc.

Stoehr, T. (1994/1999). Aqui, ahora y lo que viene: Paul Goodman y la Psicoterapia Gestalt em tiempos de crisis mundial. Santiago: Editorial Cuatro Vientos. 
Abstract: In this article we discuss Gestalt Therapy relationship with arts and aesthetics, trying to delineate the personal evolvement that Fritz Perls, Laura Perls and Paul Goodman had with arts. We consider that their personal experiences with arts constitute an aesthetic background to GestaltTherapy experiences. We describe Fritz's evolvement with theather, Laura's with dance and Goodman's with literature, trying to find historical and conceptual elements that allow framing a theoretical body witch has aesthetic criteria as important references to appreciate form. This position is fundamental to Gestalt-Therapy methodological proposal which is to work on the unity and disunity of the structure of the experience here and now. This methodological proposal intends to remake the dynamic relations of the figure and ground until it is a strong gestalt, witch expresses good contact, awareness and an energized behavior. We consider that their experience with arts has constituted a reference that oriented their view to the phenomenological reference.

Key-words: Arts, Aesthetics, Gestalt-Therapy, Experimentation.

Resumen: En este articulo, se discute la Gestalt con el Arte y la Estética, a partir del envolvimiento personal de tres de los principales formuladores de la Terapia Gestalt: Fritz Perls, Laura Perls e Paul Goodman. Consideramos que sus experiencias personales con el Arte constituyen un fondo estético de donde parten las experiencias de la Terapia Gestalt. Describimos la relación de Fritz con el teatro, de Laura con la danza y de Goodman con la literatura, buscando elementos históricos y conceptuales que nos permitan mapear y trazar algunos contornos de un cuerpo teórico que tiene, como referencias importantes para la apreciación de la forma o Gestalt, los criterios estéticos. Esos criterios están en la base de la propuesta de la terapia Gestalt, de un método sicoterápico fundamentado en la experimentación que tiene, como tarea principal, trabajar con la estrutura aquí-y-ahora. Tal método busca reatar las relaciones dinámicas de la figura-fundo hasta que se forme una Gestalt vigorosa expresando que el contacto se intensificó, que hay awareness y que el movimiento o comportamiento presente tiene energía. Creemos que la convivencia con el arte constituyó un fondo que llevó a los fundadores de la Terapia Gestalt a mirar para el viés fenomenológico.

Palabras-clave: Arte, Estética, Terapia Gestalt, Experimentación.

Mônica Botelho Alvim é Doutora em Psicologia Clínica pela Universidade de Brasília (UnB), Mestre em Psicologia Social e do Trabalho (UnB), Especialista em Gestalt-Terapia pelo Instituto de Gestalt Terapia de Brasília e graduada em Psicologia (UnB). Professora no curso de Psicologia da Universidade Católica de Brasília e diretora do Instituto de Gestalt-Terapia de Brasília, onde realiza atividades docentes, de supervisão e de pesquisa. Contempla em sua linha de pesquisa o diálogo entre psicologia, filosofia e arte, tomando como respectivos referenciais, a Gestalt-Terapia, a fenomenologia, a obra de Maurice Merleau-Ponty e o trabalho artístico de Lygia Clark 